Strength of Materials, Vol. 42, No. 1, 2010

\title{
ASSESSMENT OF BRITTLE STRENGTH OF NUCLEAR REACTOR PRESSURE VESSEL STEEL UPON WARM PRESTRESSING
}

\author{
P. V. Yasnii, I. B. Okipnyi, \\ and Yu. I. Pyndus
}

UDC 620.192 .46

\begin{abstract}
A procedure for assessing the influence of combined warm prestressing on fracture toughness of heat-resistant steel is proposed, which is based on the stress-strain state analysis by the finiteelement method (in the elastic-plastic statement) and on the local fracture criterion.
\end{abstract}

Keywords: cleavage stresses, heat-resistant steel, brittle fracture resistance, warm prestressing, plastic prestrain, finite-element method.

Introduction. Warm prestressing (WPS) of a cracked body consists in loading the body at a temperature above the ductile-brittle transition temperature, which results in a significantly higher brittle fracture resistance of the material [1]. This is an important objective for nuclear power engineering, considering that in the course of operation the reactor pressure vessel (RPV) material in the core zone is subjected to intensive neutron irradiation which induces embrittlement and an increase in the brittle-to-ductile fracture transition temperature. Consequently, the brittle fracture of RPV materials becomes possible under emergency conditions during cold water flooding of RPV.

It has been found out in [2-4] that the rise in the brittle fracture resistance upon WPS is due to a change in the crack-tip stress-strain state (SSS), i.e., to the induced system of residual compressive stresses, the crack tip blunting, and the strain hardening of the material ahead of the crack tip.

Generally, the WPS effect is caused by the following factors: (a) at high temperatures a cold-deformed structure arises which has a higher resistance to cleavage fracture, i.e., the tensile prestraining raises the material strength; (b) upon WPS the crack tip geometry is changed, the crack becomes blunted and alters the SSS of the specimen; and (c) at the relieving stage there arise residual compressive stresses in the vicinity of the crack tip due to plastic strains.

The experimental findings [5] suggest an ambiguous influence of WPS on the brittle fracture strength of heat-resistant steels. This is attributed to the interplay of the following factors which govern the crack-tip SSS changes upon WPS: the crack-tip blunting, the residual stresses, and the material hardening at the crack tip under various WPS conditions. The effect of increasing brittle fracture resistance upon WPS is observed even in the case of stable crack extension under thermomechanical loading. Pokrovskii and Ivanchenko [5] revealed that the partial stress-relieving or absence thereof during WPS did not always result in a higher brittle fracture resistance.

The objective of the present work has been to study the influence of WPS parameters on the brittle fracture strength of a heat-resistant steel and to elaborate, by means of a finite-element method (FEM), a procedure for assessing the WPS effect on the brittle strength of a heat-resistant steel by a local fracture criterion - the cleavage stress - including the influence of the stress history.

Experimental. The tests of specimens made of heat-resistant RPVsteel 15Kh2MFA were performed by means of a Mod. STM-100 servohydraulic test machine (Antonov Aeronautical Scientific-Technical Complex, Kyiv, Ukraine).

Ivan Pulyui Ternopil State Technical University, Ternopil, Ukraine. Translated from Problemy Prochnosti, No. 1, pp. 46 - 53, January - February, 2010. Original article submitted June 21, 2009. 
Steel 15Kh2MFA was studied in two structural states upon heat treatment simulating neautron-irradiation embrittlement in the middle and at the end of the RPV operation time - 15Kh2MFA (II) and 15Kh2MFA (III), respectively.

Cleavage stresses were determined through uniaxial tension of smooth cylindrical specimens at $77 \mathrm{~K}$ (the test portion diameter was 8 and $5 \mathrm{~mm}$, the measurement base was 20 and $10 \mathrm{~mm}$, respectively). The specimens had been prestrained in combined tension to a plastic strain $\varepsilon_{p l}=0.5,1.0$, and $3.0 \%$ in the temperature range between 293 and $623 \mathrm{~K}$. The cyclic stress range $\Delta \sigma$ in combined tension was 50, 90, 110, 180, and $220 \mathrm{MPa}$, frequency $f=25 \mathrm{~Hz}$.

The warm prestressing was carried out through eccentric tension of 19 -mm-thick compact specimens at $623 \mathrm{~K}$ by the scheme with complete unloading at $\bar{K}=K_{\text {Iwps }} / K_{Q}^{5 \%}=0.85$, where $K_{\text {Iwps }}$ is the largest stress intensity factor (SIF) under thermomechanical overstressing, $K_{Q}^{5 \%}$ is the SIF determined by a $5 \%$ secant in the fracture diagram at the WPS temperature. Prior to testing, primary fatigue were grown in all the specimens at a stress ratio $R=K_{\min } / K_{\max }=0.1$ and $f=40 \mathrm{~Hz}$ following the recommendations [6]. The primary crack relative length was $(0.45-0.55) b$, where is the distance between the force application axis and the specimen end). The specimen suitability for further testing was assessed according to [6] specifying that the crack nonuniformity on both specimen surfaces should be within 5\%.

Upon WPS at $293 \mathrm{~K}$ we measured the residual crack opening displacement at a distance up to $2 \mathrm{~mm}$ from the crack tip with $0.2 \mathrm{~mm}$ increments, using MIM-10 type metallurgical microscope.

The residual crack opening displacement $\delta_{r e s}$ upon unloading at $623 \mathrm{~K}$ was found from the $P-\Delta_{1}$ diagram and recomputed by the formula [7]

$$
\delta_{\text {res }}=\frac{0.4(b-l)}{0.4 b+0.6 l+r_{2}} \Delta_{1},
$$

where $r_{2}$ is the distance between the force application axis and the line of measurement of the displacement $\Delta_{1}$ and $l$ is the crack length.

The critical crack opening displacement was determined by the formula [8]

$$
\delta_{f}=\Delta_{1} \frac{\left(l_{1} / r_{1}-\Delta_{2} / \Delta_{1}\right)}{l_{1} / r_{1}-1},
$$

where $\Delta_{1}$ and $\Delta_{2}$ are the readings of pickups at distances $r_{1}$ and $r_{2}$ from the crack tip. The measurements were performed with the following condition fulfilled: $r_{1}=2-3 \mathrm{~mm}, r_{2} \geq 5-6 \mathrm{~mm}$ [6]. Since the crack front was curvilinear in most cases, the crack mean length was determined as per the guidelines [6].

The FEM calculations were carried out using ANSYS software package. For this purpose we modelled 19 -mm-thick compact specimens of steel 15Kh2MFA (II) $\left(\sigma_{0.2}=900 \mathrm{MPa}\right.$ and $\sigma_{u}=1000 \mathrm{MPa}$ at $\left.293 \mathrm{~K}\right)$. To split the model we used an eight-node two-dimensional element Plane 82 which was specified to have plastic properties and large strains. The calculations were performed for the plane strain case, allowing for the effect of kinematic hardening of the material and the Bauschinger effect. At the crack tip the FE mesh was densified to improve the calculation accuracy. The minimum element size was $25 \mu \mathrm{m}$ which approximately corresponded to a quarter of a grain size of steel 15Kh2MFA (II). The force was applied as an equivalent pressure force to the horizontal area of the half opening for the grip. In all the cases, we modelled the overstressing of the specimens in tension and combined tension at $623 \mathrm{~K}$.

Results and Discussion. Figure 1 illustrates the influence of plastic prestraining (PPS) in tension and combined tension on the cleavage stress in steel 15Kh2MFA (II).

It has been found out that as the combined-tension stress range grows and $\varepsilon_{p l}=$ const the cleavage stresses $\sigma_{c l}$ increase somewhat, in comparison to the material initial state, the increase becoming more intensive at $\varepsilon_{p l}=1.0 \%$ (Fig. 1). Note that the cleavage stresses at $\varepsilon_{p l}=3.0 \%$ are greater in static tension than in combined one [9]. 


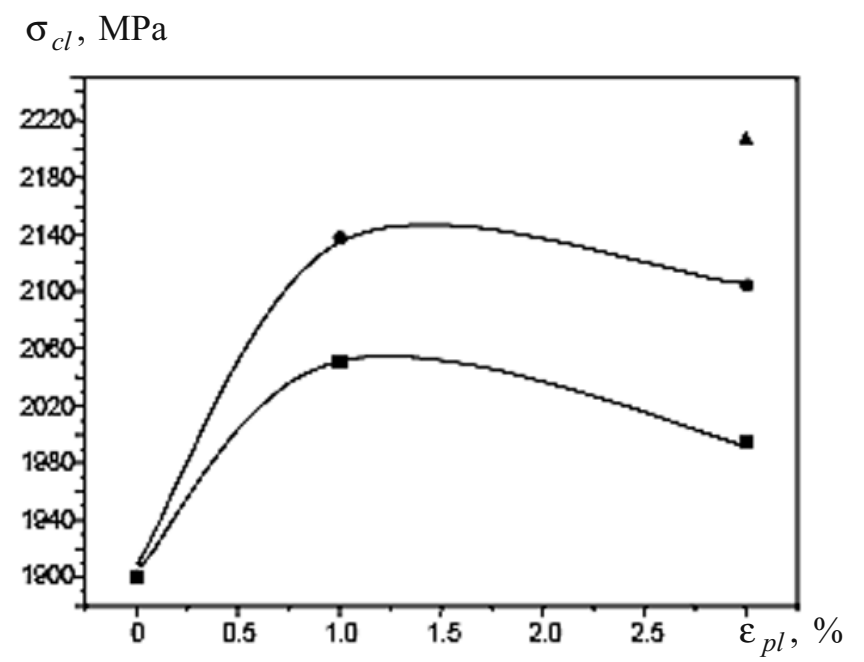

Fig. 1

$$
\delta_{\text {res }}, \mu \mathrm{m}
$$

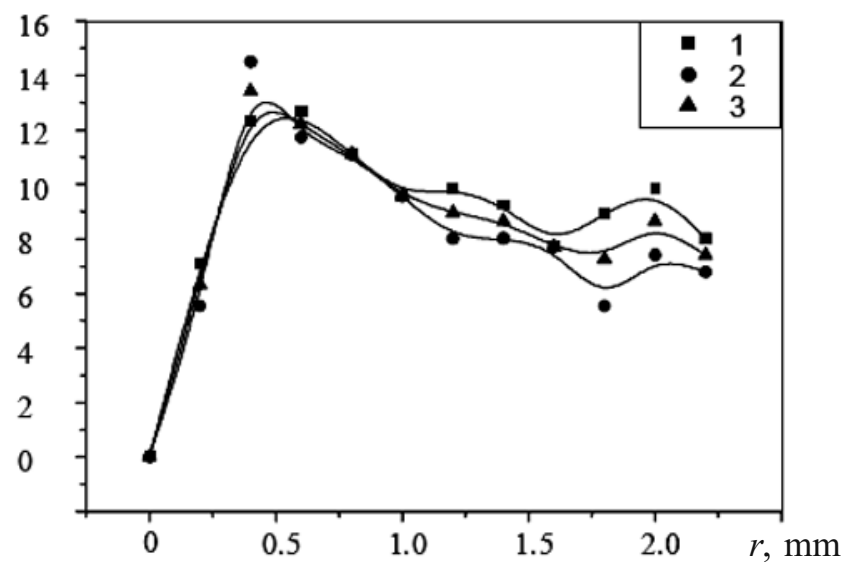

Fig. 2

Fig. 1. Cleavage stress $\sigma_{c l}$ in steel $15 \mathrm{Kh} 2 \mathrm{MFA}$ (II) as a function of PPS in tension and combined tension at $623 \mathrm{~K}:(\boldsymbol{\square}) \Delta \sigma=110 \mathrm{MPa} ;(\boldsymbol{O}) \Delta \sigma=220 \mathrm{MPa} ;(\boldsymbol{\Delta}) \Delta \sigma=0$.

Fig. 2. The residual COD $\delta_{\text {res }}(r)$ upon WPS at $623 \mathrm{~K}$ vs. the distance to the crack tip in steel 15Kh2MFA: (1) and (2) specimen front and back surfaces, respectively; (3) averaged values.

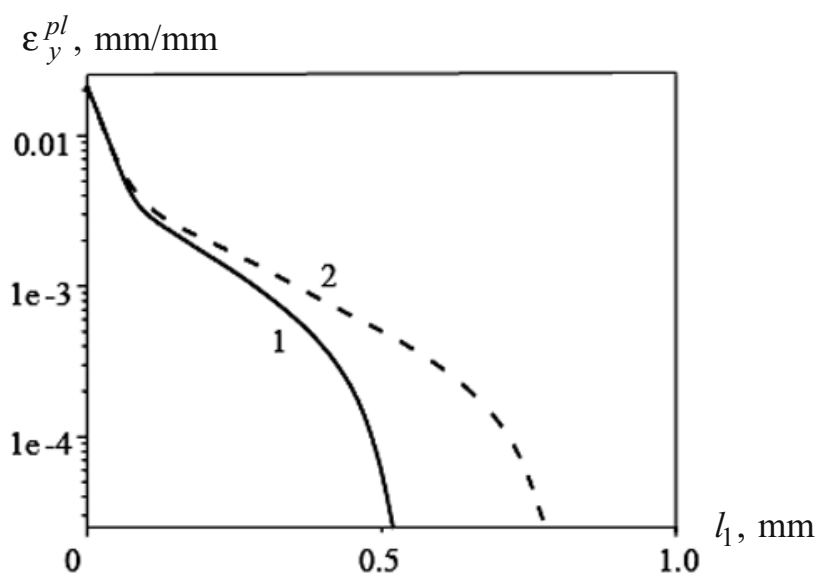

Fig. 3. Distribution of normal plastic strains at the crack tip in static (1) and combined WPS (2) at $K_{\mathrm{I}}=94 \mathrm{MPa} \sqrt{\mathrm{m}}, \Delta K=20 \mathrm{MPa} \sqrt{\mathrm{m}}$, and $T=623 \mathrm{~K}$.

Figure 2 shows the residual crack opening displacement (COD) upon WPS vs. the distance to the crack tip. The residual COD $\delta_{\text {res }}(r)$ and averaged COD on the specimen surface, as measured by means of MIM-10 microscope, depend on the distance to the crack tip. The largest value of $\delta_{r e s}(r)$ is found at a distance to the crack tip $r=0.4-0.6 \mathrm{~mm}$.

The farther from the crack tip, the smaller the residual COD. It should be mentioned that the data given in Fig. 2 are for a single specimen upon combined WPS at $623 \mathrm{~K}$ and $\bar{K}=0.85$. Similar relations were noted for the other WPS conditions.

We have revealed that in all the cases, irrespective of the loading conditions (static or combined WPS) and structural state of the steel, the brittle strength of the test material grows in comparison to the critical stress intensity factor (SIF) $K_{\mathrm{I} c}$.

As the specimen upon combined WPS is unloaded, the compressive stress distribution curve intersects the abscissa axis at a slightly larger distance in comparison to a similar curve upon static WPS. 

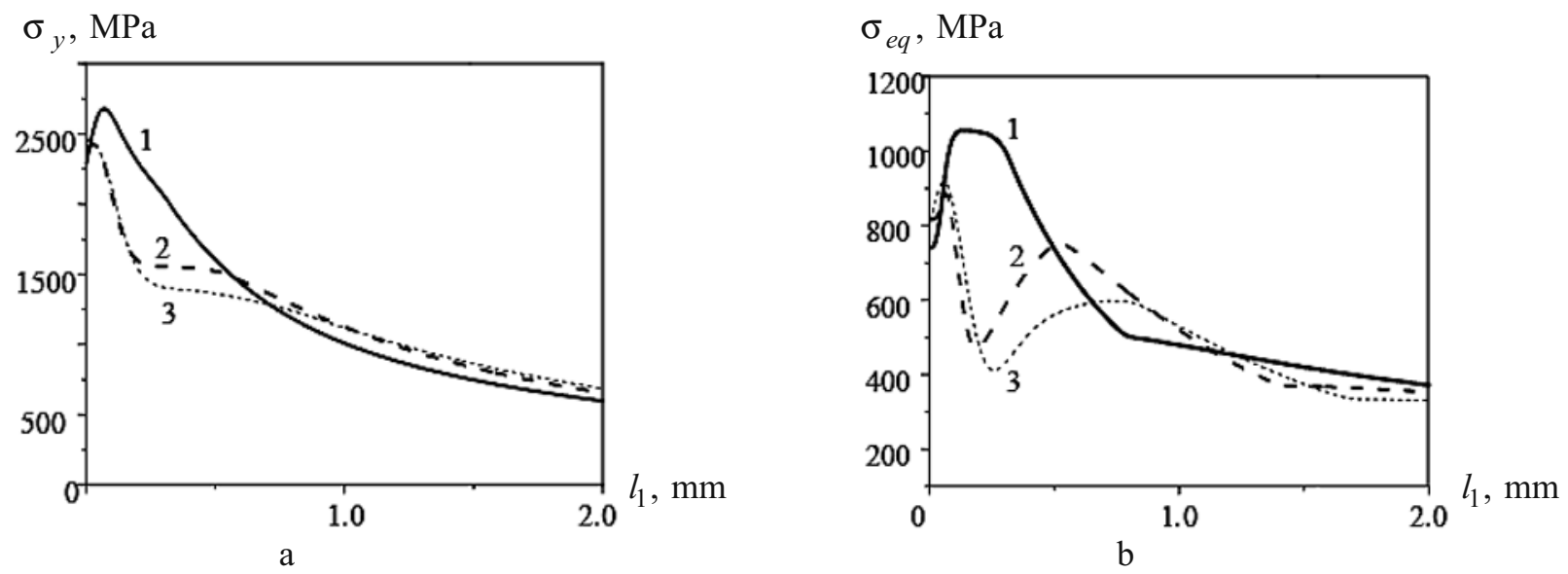

Fig. 4. Distribution of normal stresses (a) and equivalent von Mises stresses (b) at the crack tip: (1) initial state at $K_{\mathrm{I}}=80 \mathrm{MPa} \sqrt{\mathrm{m}}$ and $293 \mathrm{~K}$; (2) and (3) upon static and combined WPS, respectively.

Figure 3 shows the curves of distribution of normal plastic strains at the crack tip under the above-mentioned static and combined WPS conditions. It is evident that in the combined-WPS case the increase in the plastic strain area by about $30 \%$ results in the growth of the magnitude and extension of area of residual compressive stresses at the crack tip.

Based on the experimentally found relation between cleavage stresses and PPS (Fig. 1) and the FEMcalculated distribution of normal plastic strains (Fig. 3), we plotted a diagram of cleavage stress vs. the distance to the crack tip. It demonstrates that at some distance from the crack tip the cleavage stresses are larger in the WPS material than in the non-WPS one. Thus, the crack-tip strain hardening should be taken into account for the further research.

The experimental critical value of $\operatorname{SIF}\left(K_{\mathrm{Ic}}\right)$ for steel $15 \mathrm{Kh} 2 \mathrm{MFA}$ at $293 \mathrm{~K}$ is $80 \mathrm{MPa} \sqrt{\mathrm{m}}[10]$. We performed a FEM study of the influence of static and combined WPS on the distribution of normal stresses $\sigma_{y}$ and the von Mises equivalent stresses at $K_{\mathrm{I}}=94 \mathrm{MPa} \sqrt{\mathrm{m}}$.

The distribution of normal stresses $\sigma_{y}$ ahead of the crack tip upon static and combined WPS at $K_{\mathrm{I}}=94$ $\mathrm{MPa} \sqrt{\mathrm{m}}$ is given in Fig. 4a. Upon WPS and reloading to $K_{\mathrm{I}}=80 \mathrm{MPa} \sqrt{\mathrm{m}}$ the level of normal stresses greatly decreases (Fig. 4a, curve 2) in comparison to the initial state. However, the smallest value is noted in the case of the combined WPS versus the static one (curve 3).

A similar pattern applies to the equivalent von Mises stresses $\sigma_{e q}$ (Fig. 4b). It should be mentioned that as district from the initial material the curves of distribution of $\sigma_{e q}$ upon WPS exhibit ascending- and descendingstress segments at some distance from the crack tip.

The fractographic observations have shown that fracture in steel $15 \mathrm{Kh} 2 \mathrm{MFA}$ is initiated at some distance from the crack front $(C I D)$ through the microcleavage mechanism. Note that there could be more than one such fracture-initiation locations along the crack front, but the $C I D$ distance would be much the same. It has been revealed that the mean $C I D$ value both with and without WPS is about $300 \mu \mathrm{m}$ or $2-3$ times grain size in steel $15 \mathrm{Kh} 2 \mathrm{MFA}$.

The investigation has demonstrated that at a distance $C I D=300 \mu \mathrm{m}$ from the crack tip the normal stresses decrease significantly with increasing $K_{\mathrm{I}}$ in the combined WPS case and so do the stress intensity in reloading at $293 \mathrm{~K}$. It is obvious that it would take a larger applied force to produce the level of stresses that acted at a distance $C I D$ at $K_{\mathrm{I}}=80 \mathrm{MPa} \sqrt{\mathrm{m}}$ in the case of no WPS. Furthermore, assuming that fracture would be initiated at a distance $C I D$, one should take into consideration the strain hardening of material at this distance.

For fracture to initiate the following condition should be met: fracture will start at a distance $C I D$ as soon as the normal stresses $\sigma_{y}$ reach the cleavage stress $\sigma_{c l}$ allowing for the material's PPS at this distance. In this context, we carried out the FEM calculation of the distribution of plastic strains $\varepsilon_{p l}$ along the fatigue crack growth direction 


$$
\sigma_{y}, \sigma_{c l}, \mathrm{MPa}
$$

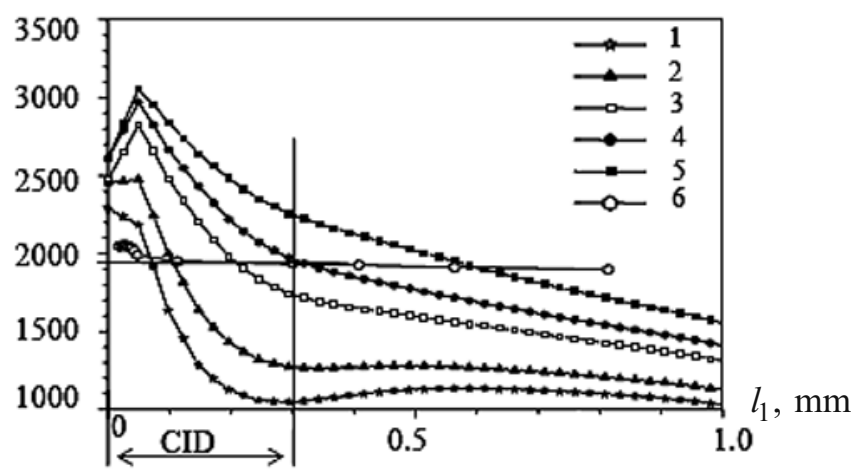

Fig. 5

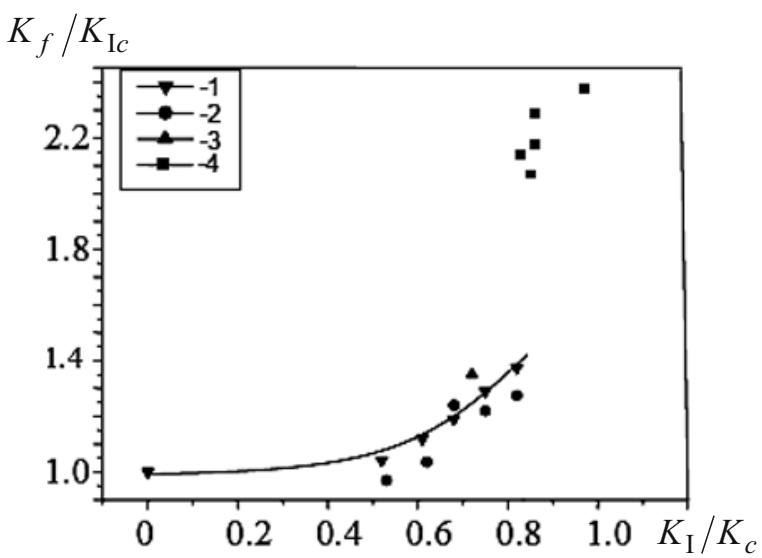

Fig. 6

Fig. 5. Distribution of normal stresses $\sigma_{y}(1-5)$ and cleavage stresses $\sigma_{c l}(6)$ at the crack tip upon combined WPS $\left(K_{\mathrm{I}}=94 \mathrm{MPa} \sqrt{\mathrm{m}}\right)$ at $K_{\max }=70(1), 80(2), 90(3), 103(4)$, and $110 \mathrm{MPa} \sqrt{\mathrm{m}}$ (5). The vertical line indicates the distance $C I D$ to the fracture initiation location.

Fig. 6. The critical SIF $K_{f}$ of steels $15 \mathrm{Kh} 2 \mathrm{MFA}$ (II) (1-3) and 15Kh2MFA (III) (4) vs. overstressing $K_{\mathrm{I}}$ in the combined WPS case: (1) FEM calculation; (2) and (4) experiment; (3) Hoagland-Hahn-Rosenfield model.

upon various levels of combined WPS and upon unloading of the specimen. Using the approximating curve of $\sigma_{c l}$ vs. $\varepsilon_{p l}$ upon PPS, we determined $\sigma_{c l}$ as a function of the distance to the crack tip along the crack extension. The calculations were performed for each level of combined WPS.

Figure 5 shows the FEM-calculated distribution of normal stresses at the crack tip upon combined WPS with $K_{\mathrm{I}}=94 \mathrm{MPa} \sqrt{\mathrm{m}}$ with increasing maximum SIF $K_{\max }$ upon WPS.

To determine the breaking force, the load was iteratively increased until the normal stresses reached the magnitude of $\sigma_{c l}$ at a distance $C I D$ allowing for PPS, i.e., till $K_{\max }=103 \mathrm{MPa} \sqrt{\mathrm{m}}$. Thus, this value was considered to be the critical SIF $K_{f}$ of the steel upon combined WPS at $K_{\mathrm{I}}=94 \mathrm{MPa} \sqrt{\mathrm{m}}$. It should be mentioned that the FEM results agree well with the experimental findings.

Using the FEM scheme outlined above, we modelled the stress-strain state at the fatigue crack tip upon combined WPS at $K_{\mathrm{I}}=70-110 \mathrm{MPa} \sqrt{\mathrm{m}}$ with a step of $10 \mathrm{MPa} \sqrt{\mathrm{m}}$.

For the assessment of the combined-WPS effect on the critical SIF $K_{f}$ for steel 15Kh2MFA (Fig. 6) the following relation is proposed:

$$
\frac{K_{f}}{K_{\mathrm{I} c}}=1+C\left(\frac{K_{\mathrm{I}}}{K_{c}}\right)^{m},
$$

where $C=0.74$ and $m=3.74$ are the parametric coefficients obtained by the least-squares method, and $K_{\mathrm{Ic}}$ and $K_{c}$ are the fracture toughness (critical SIF) in quasistatic tension at 293 and $623 \mathrm{~K}$, respectively.

Thus, using formula (3) one can optimize the WPS conditions and assess the WPS effect on the brittle strength of a RPV material.

\section{CONCLUSIONS}

1. The influence of combined plastic prestraining on the cleavage stress in steel $15 \mathrm{Kh} 2 \mathrm{MFA}$ (II) depends on both the magnitude of the static component of tension $\varepsilon_{p l}$ and the stress range of the cyclic component $\Delta \sigma$.

2. The investigation has revealed that in all the cases, irrespective of the loading conditions and steel's structural state, the brittle strength has been increased over $K_{\mathrm{I} c}$. 
3. The FEM study has demonstrated that adding a cyclic component reduces the crack-tip normal stresses in the case of the combined WPS and raises the residual compressive stresses in the case of a constant maximum SIF upon unloading. When compared to the static WPS, the combined one greatly lowers the normal stresses and the von Mises stresses at the crack tip.

4. A procedure for assessment of the WPS effect on the brittle strength of heat-resistant steel has been proposed, which is based on the SSS analysis and the local fracture criterion implying the normal stresses reaching a critical magnitude at some distance to the crack tip.

\section{REFERENCES}

1. P. A. S. Reed and J. F. Knott, "An investigation of the warm prestressing (WPS) effect in A533B weld metal," Fatigue Fract. Eng. Mater. Struct., 15, No. 12, 1251-1270 (1992).

2. I. V. Gorynin (Ed.), Radiation Damage of VVER Pressure Vessel Steel [in Russian], Énergoizdat, Moscow (1981).

3. V. V. Pokrovsky, V. T. Troshchenko, V. G. Kaplunenko, et al., "A promising method for enhancing resistance of pressure vessels to brittle fracture," Int. J. Press. Vess. Piping, 58, 9-24 (1994).

4. H. Nakamura, H. Kobayashi, N. Kodaira and H. Nakarama, "On the influence of prestressing on fracture toughness of A533B1 steel,” in: Proc. Int. Conf. Fracture (Cannes, March-April 1981), NIIInforménergomash, Moscow (1985), Issue 3, pp. 27-38.

5. V. V. Pokrovskii and A. G. Ivanchenko, "Influence of the modes of thermomechanical preloading on the resistance of heat-resistant steels to brittle fracture," Strength Mater., 31, No. 2, 200-209 (1999).

6. RD-50-345-82. Method Instructions. Strength Calculations and Tests. Mechanical Test Methods for Metals. Determination of Crack Growth Resistance (Fracture Toughness) under Cyclic Loading [in Russian], Izd. Standartov, Moscow (1986).

7. K. N. Schwalbe, Basic Engineering Methods of Fracture Mechanics and Fatigue, GKSS-Forschugszentrum Geesthacht, November 2001.

8. V. V. Panasyuk (Ed.), Fracture Mechanics and Strength of Materials. Handbook [in Russian], in 4 volumes. Vol. 3: Short-Time Fracture Toughness Characteristics and Methods for Their Determination, Naukova Dumka, Kiev (1988).

9. V. Hutsaylyuk, O. Tsyrulnyk, I. Okipny, and P. Yasniy, "The effect plastic deformation with hydrogenation on 15Cr2MFA heat-resistant steel cleavage stress," in: Proc. Int. Conf. "Mechanika 2006" (Kaunas, Apr. 6-7, 2006), pp. 95-98.

10. P. V. Yasnii, V. Yu. Podkol'zin, and Ya. O. Koval'chuk, A Method of Enhancing Crack-Propagation Resistance of a Structural Element [in Ukrainian], Ukrainian Patent No. 23231A. Effective as of 19 May 1998. 